\title{
Nephropathy in the course of IgA vasculitis - case report
}

\author{
Katarzyna Dyga', Majka Jaszczura², Piotr Adamczyk³, Omar Bjanid³, \\ Aurelia Morawiec-Knysak', Maria Szczepańska \\ 'Department of Paediatric Nephrology, Teaching Hospital No. 1, Medical University of Silesia, Zabrze, Poland \\ ${ }^{2}$ Department of Paediatrics, Teaching Hospital No. 1, Medical University of Silesia, Zabrze, Poland \\ ${ }^{3}$ Chair and Department of Paediatrics, School of Medicine with the Division of Dentistry in Zabrze, \\ Medical University of Silesia, Zabrze, Poland
}

\section{ABSTRACT}

IgA vasculitis (IgAV), formerly known as Henoch-Schönlein purpura (HSP), is the most common form of systemic vasculitis in children. Nephrological symptoms in the course of the disease are observed in $30-50 \%$ of children. The prognosis for maintaining normal kidney function is good in most patients; however, it depends on the primary clinical manifestation. Our aim was to present a case of a girl with nephropathy in the course of IgAV in the form of nephritic-nephrotic syndrome, who, despite early and intensive immunosuppressive treatment, revealed development of end-stage renal failure (ESRF) within two years. We also discuss the treatment of severe nephropathy in the course of $\operatorname{IgAV}$, in accordance with current recommendations, which still remains a great challenge and does not guarantee slower progression of the disease.

\section{KEY WORDS:}

children, IgA vasculitis, nephropathy.

\section{INTRODUCTION}

IgA vasculitis (IgAV), formerly known as HenochSchönlein purpura (HSP), is the most common form of systemic vasculitis in children. The diagnosis of IgAV should be based on the classification criteria developed jointly by the Paediatric Rheumatology International Trials Organisation (PRINTO), the European League Against Rheumatism (EULAR), and the Paediatric Rheumatology European Society (PRES), which include the diagnosis of purpura as the main symptom and one of four additional criteria, i.e. abdominal pain, arthritis or joint pain, symptoms of nephropathy (proteinuria $>0.3 \mathrm{~g} / 24 \mathrm{~h}$ or $>30 \mathrm{mg} / \mathrm{mmol}$ of urine albumin/creatinine ratio on a spot morning sample, haematuria $>5$ erythrocytes/high power field), and a typical picture in histopathological examination of the skin or kidney biopsy [1]. The course of IgAV is usually mild and self-limiting, but in 30-50\% of patients it may lead to renal complications [2], which may take various forms: from asymptomatic microscopic haematuria, through fully expressed nephritic or nephrotic syndrome, to rapidly progressive glomerulonephritis (RPGN).

Nephrological symptoms usually appear early - in $85 \%$ of cases in the first month of the disease, in $91 \%$ in six weeks, and in $97 \%$ in six months after the onset of the first symptoms of the disease [3]. Risk factors for development of nephropathy in the course of IgAV include male gender, age over 10 years, severe gastrointestinal symptoms, long-lasting skin lesions, inflammation or pain of joints, and some deviations in laboratory tests such as leukocytosis above $15 \times 10^{9} / 1$, platelet counts above $500 \times 10^{9} / 1$, elevated serum anti-streptolysin $\mathrm{O}(\mathrm{ASO})$ titre, and decreased serum c3 component of the complement concentration $[4,5]$. For the majority of patients, prognosis for the maintenance of normal kidney function is good, whereas adverse prognostic factors for ESRF in adults with IgAV include renal dysfunction persistent from the onset

\section{ADDRESS FOR CORRESPONDENCE:}

Katarzyna Dyga, Department of Paediatric Nephrology, Teaching Hospital No. 1, Medical University of Silesia, Zabrze, 13/15 3 Maja St., 41-800 Zabrze, Poland, e-mail: katarzynadyga@wp.pl 
of the disease (creatinine level $>1.35 \mathrm{mg} / \mathrm{dl}$ ), proteinuria above $1 \mathrm{~g}$ /day and fibrin necrosis, signs of damage to the interstitium in biopsy (> 10\% interstitial fibrosis), and/or glomerulosclerosis ( $>20 \%$ assessed in the biopsy) $[6,7]$.

Our aim was to describe a case of a girl with nephropathy in the course of IgAV, which, despite early and intensive immunosuppressive treatment, within two years revealed the development of ESRF.

\section{CASE REPORT}

In December 2015, a 15-year-old girl was admitted to the Department of Paediatrics due to the symptoms of IgA vasculitis in the form of purpura on the skin of lower extremities and buttocks accompanied by pain in legs and swelling of the ankles. In the history, during one week preceding the admission, the patient was treated with an antibiotic due to tonsillitis. Physical examination additionally revealed pharyngitis, tonsillar hypertrophy, and cervical lymphadenopathy. Laboratory tests carried out, apart from slightly increased serum D-dimer concentration $(3.68 \mu \mathrm{g} / \mathrm{ml}, \mathrm{n}: 0-0.5 \mu \mathrm{g} / \mathrm{ml})$, high serum ASO titre (441 IU/l, n: 0-150 IU/ml), and elevated serum immunoglobulin A level (2.97 g/l, n: 0.47-2.49 g/l), were within the normal range, stool occult blood examination was negative, and the urine tests performed daily were normal. The diagnostics was extended by the determination of antinuclear antibodies (ANA Screen by ELISA in the IgG class), the result of which was negative.

During the seven days of hospitalisation, antibiotic therapy was continued as well as vascular wall protecting drugs, and the bed regimen was used without observing relapse of the purpura. The patient, in a general good condition, was discharged home with the recommendation to perform a urinalysis every two weeks for a period of six months, and each time in the case of recurrence of skin lesions. After less than two weeks, the girl was diagnosed with a recurrence of purpura in the form of massive haemorrhagic rash on the skin of forearms, buttocks, and lower extremities. Physical examination also revealed swellings of joints of upper and lower limbs and abdominal tenderness. The urinalysis showed overt range proteinuria (6.6 g/l) and erythrocyturia (10-20 erythrocytes/high power field). The patient was admitted to the Children's Nephrology Department in moderate general condition for further diagnostics and treatment.

Laboratory tests showed elevated inflammatory parameters (CRP $29 \mathrm{mg} / \mathrm{l}, \mathrm{n}$ : 0-5 mg/l), increased serum ASO titre (314 IU/l) and high serum concentration of immunoglobulin A (3.85 g/l). The total serum proteins and albumin concentrations as well cholesterolaemia and triglyceridaemia were normal. The 24-hour urine collection revealed the proteinuria of $3.6 \mathrm{~g} /$ day and increased erythrocyturia (Addis count about $12 \mathrm{ml} /$ day, n: 0.13-2 ml/ day). Diagnostics were extended by virological tests (anti$\mathrm{HCV}, \mathrm{HBsAg}$ ), assessment of anti-glomerular basement membrane antibodies (anti-GBM), anti-myeloperoxidase antibodies (anti-MPO), antibodies against proteinase 3 (anti-PR3), repeated ANA Screen, and assessment of c3 and $c 4$ components of the complement, which were within normal range and allowed us to preliminary preclusion of other than IgAV cause of nephropathy. Ultrasound of the abdomen revealed slightly increased cortex echogenicity of both kidneys.

Therapeutically, empiric antibiotic therapy, parenteral hydration, analgesic therapy, and vascular wall protecting drugs were used. Due to persistent nephrotic proteinuria, it was decided to start methylprednisolone intravenous therapy at a dose of $60 \mathrm{mg} /$ day. During the next days we observed deterioration of the patient's general condition with vomiting, abdominal pain, diarrhoea, and peripheral oedema. The laboratory tests showed gradually increasing serum creatinine concentration - the highest being $87 \mu \mathrm{mol} / \mathrm{l}$ (estimated glomerular filtration rate - eGFR, estimated according to the new Schwartz formula was $66 \mathrm{ml} / \mathrm{min} / 1.73 \mathrm{~m}^{2}$ ), increased serum urea concentration (12.7 mmol/l, n: $2.76-8.07 \mathrm{mmol} / \mathrm{l})$, hypoproteinaemia (48.1 g/l, n: 60-80 g/l), and hypoalbuminaemia (30 g/l, n: 32-45 g/l). The serum cholesterol and triglyceride concentrations were within the normal range. In 24hour urine collection persistent proteinuria ( $5.7 \mathrm{~g} /$ day) and massive erythrocyturia were observed. Additionally, the presence of occult blood in the stool was revealed. Suspecting a RPGN, a kidney biopsy was performed. Pending its outcome, the steroid therapy was intensified using three pulses of methylprednisolone at a dose of $10 \mathrm{mg} / \mathrm{kg}$ body weight every 48 hours. Obtained histopathological results of the biopsy specimen corresponded to class IIIa of pathomorphological changes in patients with IgAV nephropathy according to the International Study of Kidney Disease in Childhood (ISKDC) classification [8]. In connection with the obtained result of kidney biopsy and persistent nephrotic proteinuria, it was decided to add cyclophosphamide (CYP) to the therapy. The first two doses of the drug (I: $500 \mathrm{mg}$, i.e. about $320 \mathrm{mg} / \mathrm{m}^{2}$, II: $750 \mathrm{mg}$, i.e. about $480 \mathrm{mg} / \mathrm{m}^{2}$ ) were administered intravenously to the patient during hospitalisation.

In the period from January to June 2016, the girl received a total of six doses of CYP (doses III-VI in an amount of approximately $480 \mathrm{mg} / \mathrm{m}^{2}$ administered every four weeks) - the total cumulative dose was approximately $77 \mathrm{mg} / \mathrm{kg}$ body weight. In addition, the patient at that time remained on systematic and progressively reduced steroid therapy with prednisone, permanent renoprotective treatment with angiotensin-converting enzyme inhibitors (ACEi), and antihypertensive treatment. In spite of intensive immunosuppressive treatment, only stabilisation of proteinuria to $3 \mathrm{~g}$ /day in 24-hour urine collection was achieved, with persistent massive erythrocyturia and elevated serum creatinine concentration $\left(100 \mu \mathrm{mol} / \mathrm{l}\right.$, eGFR $\left.58.4 \mathrm{ml} / \mathrm{min} / 1.73 \mathrm{~m}^{2}\right)$. In the period of about nine months from the diagnosis, it was decided 


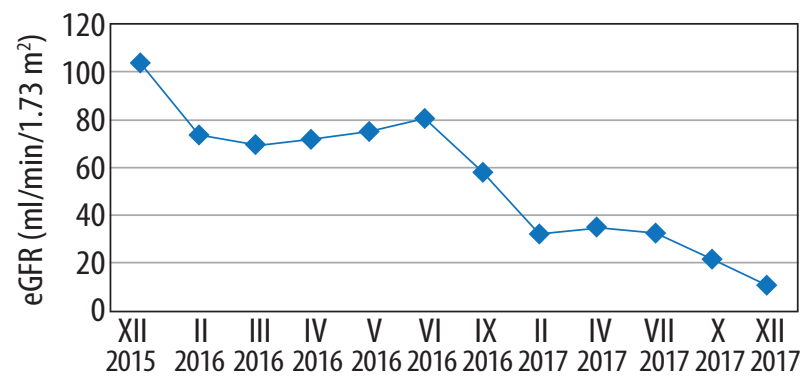

FIGURE 1. Gradual progression of chronic kidney disease

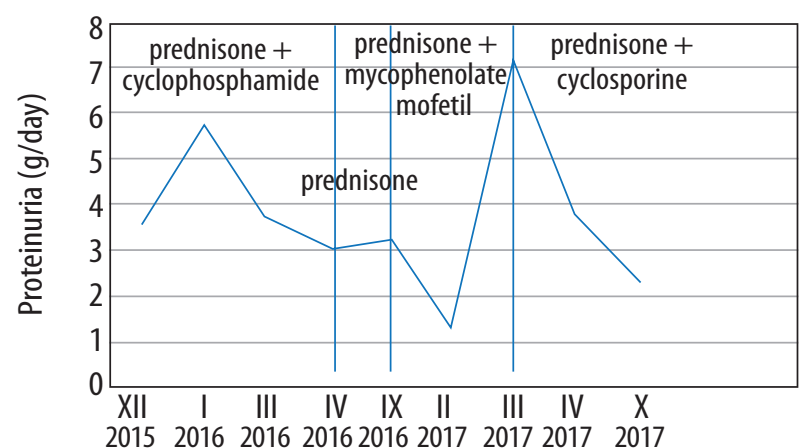

FIGURE 2. Variability of proteinuria during modification of immunosuppressive therapy

to administer mycophenolate mofetil (MMF) at a dose of $2 \mathrm{~g} /$ day. Renoprotective treatment has also been modified by the addition of an angiotensin receptor blocker (ARB). Over the next five months, despite the treatment, the serum creatinine concentration gradually increased up to $177 \mu \mathrm{mol} / \mathrm{l}$ (eGFR: $38.6 \mathrm{ml} / \mathrm{min} / 1.73 \mathrm{~m}^{2}$ ), and progressive hyperuricaemia $(372 \mu \mathrm{mol} / \mathrm{l}, \mathrm{n}: 142.8-339.2$ $\mu \mathrm{mol} / \mathrm{l})$, as well as hypercholesterolaemia $(8.06 \mathrm{mmol} / \mathrm{l}$, $\mathrm{n}: 3-5 \mathrm{mmol} / \mathrm{l})$ with hypertriglyceridaemia $(5 \mathrm{mmol} / \mathrm{l}$, $\mathrm{n}:<1.7 \mathrm{mmol} / \mathrm{l})$ were observed. Control 24-hour urine collection revealed proteinuria up to $1.3 \mathrm{~g} /$ day and erythrocyturia. We also found incomplete compliance, which could also have had a significant impact on the progression of the disease. The patient was informed about the necessity of regular medication intake. It was decided to continue the treatment with MMF (at a dose $1.2 \mathrm{~g} / \mathrm{m}^{2}$ ) and prednisone. Additionally, hydrochlorothiazide, furosemide, and allopurinol were added to the therapy and the administration of ACEi was discontinued. After another month, due to the observed progression of proteinuria and further lowering of eGFR, the immunosuppressive treatment was modified by replacing MMF with cyclosporine (CsA), initially at a dose of about $1.8 \mathrm{mg} / \mathrm{kg}$ body weight/day under strict control of drug concentration, renal function, and daily urine output. A reduction in 24-hour proteinuria to a value of $2.3 \mathrm{~g}$ was obtained with constant erythrocyturia and increased serum concentration of creatinine $(131 \mu \mathrm{mol} / \mathrm{l}$, eGFR: $\left.44.2 \mathrm{ml} / \mathrm{min} / 1.73 \mathrm{~m}^{2}\right)$, urea $(13.4 \mathrm{mmol} / \mathrm{l})$, and uric acid ( $410 \mu \mathrm{mol} / \mathrm{l})$. During the subsequent nine months, progression of chronic kidney disease (CKD) to the ESRF was observed. Currently, the girl is being treated with automated peritoneal dialysis during qualification for kidney transplantation.

The progression of CKD and follow-up of proteinuria are shown in sequence in Figure 1 and Figure 2.

\section{DISCUSSION}

During the onset of the disease our patient presented only with a purpura of a typical location and pain in the lower extremities with accompanying swollen ankle joints. However, the age of over 10 years, joint symptoms, and elevated serum ASO titre constituted risk factors for developing nephropathy reported by Chan et al. [5]. Two weeks later recurrence of purpura with renal complications was observed. Regarding the relapses of IgAV, Calvo-Río et al. reported that they may occur in about one third of the patients, more often in patients with gastrointestinal and joint symptoms [9].

The kidney biopsy during IgAV should be considered when the acute renal impairment or nephritic syndrome are observed at the initial period, and when nephrotic syndrome with normal renal function persists at four weeks or nephrotic syndrome proteinuria (urine protein/ creatinine ratio $>250 \mathrm{mg} / \mathrm{mmol}$ ) is observed at 4-6 weeks or persistent proteinuria (urine protein/creatinine ratio $>100 \mathrm{mg} / \mathrm{mmol}$ ) occurs for more than three months [10]. In our patient persistent nephrotic proteinuria and decreased eGFR were the reason that a kidney biopsy was performed. Histopathological results of the biopsy specimen corresponded to IIIa (presence of crescents in less than $50 \%$ of glomeruli) of pathomorphological changes in patients with IgAV nephropathy according to the ISKDC classification [8]. According to the recommendations of KDIGO (Kidney Disease: Improving Global Outcomes) from 2012, in the case of persistent proteinuria of 0.5$1 \mathrm{~g} /$ day $/ 1.73 \mathrm{~m}^{2}$ in patients with $\mathrm{IgAV}$, it is recommended to include ACEi or ARB in the treatment. When the treatment described above is ineffective and the eGFR value remains above $50 \mathrm{ml} / \mathrm{min} / 1.73 \mathrm{~m}^{2}$, it is recommended to use the procedure as in IgA nephropathy, involving the introduction of steroid therapy for a period of six months. In the case of children with glomerular crescents in renal biopsy (more than $50 \%$ of assessed glomeruli) and clinical manifestations of nephrotic syndrome and/or worsening renal function, treatment is recommended as in crescent nephropathy IgA involving the use of steroids with simultaneous application of CYP [11]. According to the current recommendations, our patient should only be given steroid therapy for six months. However, a more intensive treatment was implemented because of inauspicious clinical picture. It is worth mentioning that the current recommendations regarding therapeutic management in patients with nephropathy in the course of IgAV are based on developed standards of management in patients with IgA nephropathy [12]. Because of the clinical, 
pathophysiological, and histological differences between these diseases, which Davin emphasises in his work [12], it is obvious that they require different treatment. Therefore, more and more is being discussed about the need to conduct randomised surveys evaluating the course of treatment in children with nephropathy in the course of IgAV, and to change actual recommendations.

\section{CONCLUSIONS}

In our patient, despite early and intensive immunosuppressive treatment, we observed the development of ESRF within two years after onset of the disease. In a publication concerning one of the longest observations of renal function in adults who underwent IgAV during childhood, it was confirmed that the prognosis is associated with primary clinical manifestation of the disease [13]. In the case of nephropathy in the form of nephritic-nephrotic syndrome, the risk of developing CKD is the highest and is over $50 \%$, while the risk of ESRF in the case of persistence of nephrotic syndrome is $41 \%$ [12]. It is possible that the rapid progression of the disease in our patient could also be affected by the lack of full compliance with therapeutic recommendations. Currently, the girl is treated by renal replacement therapy during qualification for kidney transplantation. The risk of relapse of IgAV after kidney transplantation, depending on the source, is $33 \%$ to $50 \%$ [14], whereas the risk of graft loss from recurrence in a first graft, as reported by Kanaan et al., is $7.5 \%$ at 10 years [15].

\section{DISCLOSURE}

The authors declare no conflict of interest.

\section{REFERENCES}

1. Ozen S, Pistorio A, Iusan S, et al. EURAL/PRINTO/PRES criteria for Henoch-Schöenlein purpura, childhood polyarteritis nodosa, childhood Wegener granulomatosis and childhood Takayasu arteritis: Ankara 2008. Part II: Final classification criteria. Ann Rheum Dis 2010; 69: 798-806.

2. Pohl M. Henoch- Schönlein purpura nephritis. Pediatr Nephrol 2015; 30: 245-252.

3. Narchi H. Risk of long term renal impairment and duration of follow up recommended for Henoch-Schönlein purpura with normal or minimal urinary findings: a systematic review. Arch Dis Child 2005; 90: 916-920.

4. Gonzáles-Gay M, López-Mejías R, Pina T, et al. IgA Vasculitis: Genetics and Clinical and Therapeutic Management. CurrRheumatol Rep 2018; 20: 24.

5. Chan H, Tang Y-L, Lv X-H, et al. Risk Factors Associated with Renal Involvement in Childhood Henoch-Schönlein Purpura: A Meta-Analysis. PLoS ONE 2016; 11: e0167346.

6. Audemard-Verger A, Pillebout E, Guillevin L, et al. IgA vasculitis (Henoch-Shönlein purpura) in adults: Diagnostic and therapeutic aspects. Autoimmun Rev 2015; 14: 579-585.
7. Heleniak Z, Dębska-Ślizień A, Ptasińska-Perkowska A, et al. Zapalenie naczyń związane z IgA (plamica Henocha-Shönleina) a nerki. Forum Nefrol 2014; 7: 159-168.

8. Koskela M, Ylinen E, Unkonmaanaho E-M, et al. The ISKDC classification and a new semiquantitative classification for predicting outcomes of Henoch-Schönlein purpura nephritis. Pediatr Nephrol 2017; 32: 1201-1209.

9. Calvo-Río V, Hernández JL. Ortiz-Sanjuán F, et al. Relapses in patients with Henoch-Schönlein purpura. Analysis of 417 patients from a single center. Medicine (Baltimore) 2016; 95: e4217.

10. McCarthy HJ, Tizard EJ. Clinical practice: Diagnosis and management of Henoch-Schönlein purpura. Eur J Pediatr 2010; 169: 643-650.

11. Radhakrishnan J, Cattran DC. The KDIGO practice guideline on glomerulonephritis: reading between the (guide)lines-application to the individual patient. Kidney Int 2012; 82: 540-856.

12. Davin JC, Coppo R. Henoch-Schönlein purpura nephritis in children. Nat Rev Nephrol 2014; 10: 563-573.

13. Ronkainen J, Nuutinen M, Koskimies O. The adult kidney 24 years after childhood Henoch-Schönlein purpura: a retrospective cohort study. Lancet 2002; 360: 666-670.

14. Grenda R. Nefropatia w przebiegu plamicy Henocha-Schönleina. Nefrol Dial Pol 2008; 12: 186-192.

15. Kanaan N, Mourad G, Thervet E, et al. Recurrence and graft loss after kidney transplantation for Henoch-Schönlein purpura nephritis: a multicenter analysis. Clin J Am Soc Nephrol 2011; 6: 1768-1772. 